HELMINTHOLOGIA, 53, 3: 233 - 242, 2016

\title{
Parasitological survey of Polish primitive horses (Equus caballus gmelini Ant.): influence of age, sex and management strategies on the parasite community
}

\author{
K. SLIVINSKA ${ }^{1}$, V. KHARCHENKO ${ }^{1}$, Z. WRÓBLEWSKI' ${ }^{2}$ J. GAWOR ${ }^{3}$, T. KUZMINA ${ }^{\text {1* }}$
}

1I. I. Schmalhausen Institute of Zoology, NAS of Ukraine, vul. B. Khmelnitskogo 15, Kyiv, 01601, Ukraine, E-mail: horsecez@gmail.com, vit@izan.kiev.ua, *taniak@izan.kiev.ua; ${ }^{2}$ eterinary Private Practice, Pisz, Mickiewicza 41, Poland, E-mail: zbigwrob@op.pl, ${ }^{3}$ W. Stefanski Institute of Parasitology of Polish Academy of Sciences, Warsaw,

ul. Twarda 51/55, Poland, E-mail: gaworj@twarda.pan.pl

\section{Article info}

Received February 25, 2016 Accepted May 12, 2016

\section{Summary}

An extensive analysis of the relationship between age, sex, and different types of management strategies relative to the gastrointestinal parasite community of Polish primitive horses was performed on 124 horses maintained in nine farms from four regions of Poland. The horses ( 96 females and 28 males) were housed in three types of management strategies: stabled (ST), free-ranging (FR) and semi-free (SF). These horses also were divided into three age groups: $<3$ years, $3-10$ years and $>10$ years old. The gastrointestinal parasites were collected following deworming of all horses with anthelmintics containing the macrocyclic lactones and praziquantel. Totally, 66,192 parasite specimens were collected and identified. The analysis of dependence of horse infection with intestinal nematodes using sex, age and management strategies demonstrated that females had significantly heavier infections of strongylids. Young horses ( $<3$ years old) had higher infections of Parascaris equorum and Strongyloides westeri. Free ranging horses were more infected with strongylids, Oxyuris equi and Gasterophilus intestinalis. Thirty-five nematode species, one cestode and one species of the botfly larvae of Gasterophilus were found. Diagnostic deworming examination revealed presence of Parascaris equorum in $27.4 \%$, Oxyuris equi in $38.7 \%$, Habronema muscae in $16.9 \%$, Anoplocephala perfoliata in $42.7 \%$ and Gasterophilus intestinalis in $46.8 \%$ in the Polish primitive horses examined. Strongyloides westeri presence was confirmed only by fecal samples examination; threadworms were not observed in these horses after deworming. In the strongylid community, 31 species ( 6 of subfamily Strongylinae and 25 of Cyathostominae) were found. Significant differences in prevalence of separate strongylid species, or their proportions in the communities were not observed between females and males, or between age groups $(p>0.05)$. The highest species diversity ( $n=30$ or 31 ) was observed in the FR horses, the lowest $(n=15)$ - in ST horses. The FR horses had higher prevalence and proportion of large strongyles in the community, in comparison to SF or ST horses $(p<0.05)$.

Keywords: Polish primitive horses; EPG values; Equus caballus gmelini, Strongylidae, Parascaris equorum; Strongyliodes westeri; Anoplocephala perfoliata; gastrointestinal parasites

\section{Introduction}

Polish primitive horses or the Polish Konik horse (Equus caballus gmelini Antonius form silvatica Vetulani) is the primitive horse breed originating directly from the tarpans (Pruski, 1959; Pruski \& Jaworowska, 1963; Kownacki, 1984; Pasicka, 2013). This semiwild breed of horse is a natural relic and a precious part of Poland's and Europe's heritage. Due to their small numbers these 
horses are classified as an endangered breed and have been included into the program for protection of threatened local breeds (Jaworski, 2007). Analysis of data collected in 2010 documented the national population of Polish primitive horses to be 150 mares and 40 stallions in state breeding centers; and 550 mares and 130 stallions under nature conditions (Jezierski et al., 2012).

Polish primitive horses are maintained under three different strategies: stabled (ST), free-ranging (FR) and semi-free (SF) management systems (Jezierski \& Jaworski, 2008). The stabled system is traditional - the horses are kept and fed in stables or on small paddocks. In the free-ranging system, horses are kept in natural reserves as free ranging animals under nearly natural conditions without human care (Jaworski, 2007). The semi-free conditions are characterized by keeping the horses in large reserve areas, similarly to free-ranging conditions, but the horses are periodically in contact with people, moved onto small paddocks, and can be used for various types of work (Jezierski \& Jaworski, 2006, 2008). Grazing is very important in all three management strategies and horses must spend most of their time on pastures or paddocks (Jaworski \& Jaszczycska, 2004).

Worldwide, wild and domestic horses kept under different management strategies are infected with gastrointestinal parasites that cause significant problems to their health (Lichtenfels, 1975; Dvojnos \& Kharchenko, 1994; Hodgkinson, 2006). Previous studies monitoring the gastrointestinal parasite community of Polish primitive horses from different reserves indicated high levels of infections with intestinal parasites, especially with strongylids, which without anthelmintic treatments reached infection levels estimated as thousands of eggs per gram of feces (Romaniuk et al., 2001, 2002, 2003). Even though anthelmintic treatments significantly reduces the burden levels of intestinal parasites, regular treatments

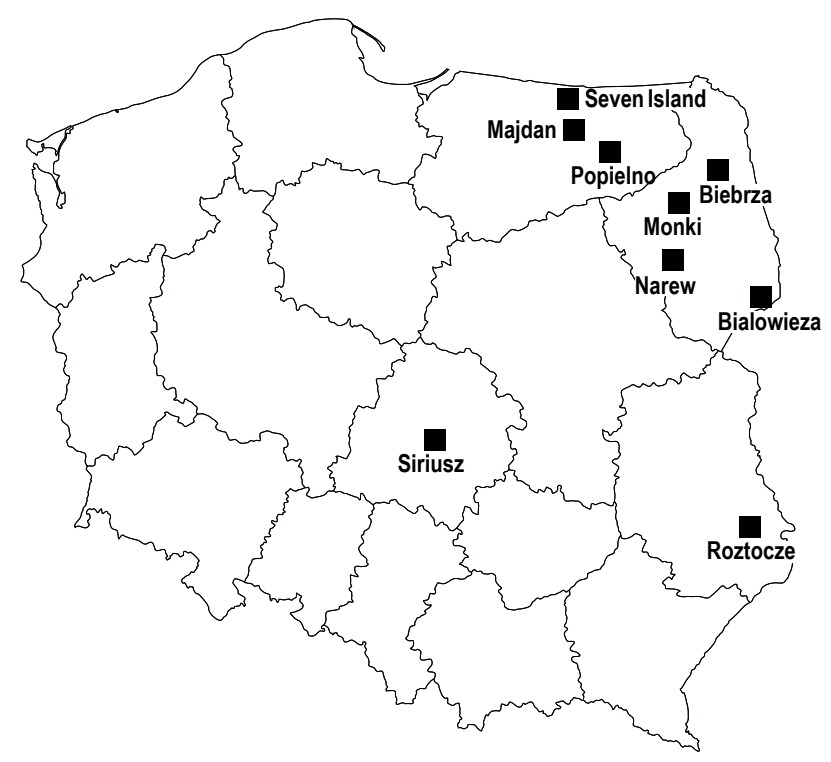

Fig. 1. Locations of nine Polish primitive horse farms included into the study in Poland before moving them to new places are not routinely practiced in Poland; therefore, their parasites may spread into new territories (Romaniuk et al., 2007; Slivinska et al., 2010).

Several studies on the gastrointestinal parasites in the Polish primitive horses from different reserves in Poland were performed recently (Slivinska et al., 2009; 2012; 2013; 2016). However, our knowledge on the influence of various internal and external factors such as age, sex and types of management strategies on the gastrointestinal parasite community is still limited. The aim of the present study was to perform an extensive analysis of relations between age, sex and management strategies and the gastrointestinal parasite communities of Polish primitive horses maintained on nine horse farms in north-eastern and central Poland. Special analysis of the strongylid community structure in the horses of different sexes, ages and from different farms also was carried out.

\section{Materials and Methods}

\section{Study areas and horses}

Our study was carried out on nine farms with different types of management strategies from four regions of Poland (Fig. 1): the Warminsko-Mazurskie region - Popielno forest reserve (Popielno; $53^{\circ} 45^{\prime} 16.4^{\prime \prime N}$; $\left.21^{\circ} 37^{\prime} 42.1^{\prime \prime E}\right)$, Seven Island Lake Nature Reserve (Seven Island; $54^{\circ} 18^{\prime} \mathrm{N} 21^{\circ} 34^{\prime} \mathrm{E}$ ), and a private ecological farm "Majdan" near Ruczane-Nida town (Majdan; $53^{\circ} 39^{\prime} 16^{\prime \prime} \mathrm{N}$ $21^{\circ} 29^{\prime} 1$ "E); the Podlaskie region - the Bialowieza National Park (Bialowieza; $52^{\circ} 45^{\prime} 7.66 " \mathrm{~N} 23^{\circ} 52^{\prime} 44.86 " \mathrm{E}$ ), Biebrza National Park

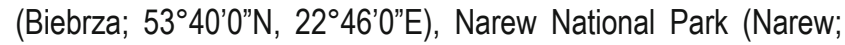
$53^{\circ} 03^{\prime} 00^{\prime \prime} \mathrm{N} 22^{\circ} 24^{\prime} 15^{\prime \prime E}$ ) and a private farm near Monki town (Monki; 53 $\left.{ }^{\circ} 24^{\prime} \mathrm{N} 22^{\circ} 48^{\prime} \mathrm{E}\right)$; Lubelskie region - Roztocze National

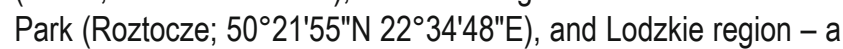
breeding farm "Siriusz" near Lodz city (Siriusz; $51^{\circ} 47^{\prime} \mathrm{N} 19^{\circ} 28^{\prime} \mathrm{E}$ ). Totally, 124 Polish primitive horses ( 96 females and 28 males) were included in this study during spring seasons in 2008 - 2012. According to the different types of management strategies, all horses were divided into three groups: 1) stabled horses (ST) ( $n=46)$; 2) semi-free horses (SF) ( $n=30)$, and 3 ) free-ranging horses (FR) $(n=48)$. All horses examined were divided into three age groups: foals and horses less than 3 years old $(n=53)$, horses from 3 to 10 years old $(n=51)$ and old horses of more than 10 years old $(n=20)$ (Table 1). All horses had natural levels of parasite infections and had not been treated with any anthelmintics at least for 3 month before the study began.

\section{Parasitological examinations}

The level of horse infections with gastro-intestinal parasites was determined by the coprological McMaster technique with sensitivity of 25 eggs per gram of feces (EPG value) (Herd, 1992). Fresh fecal samples were collected per rectum from every individual horse, or from the ground.

Gastrointestinal parasites (nematodes and cestodes) were collected from every individual horse in vivo by the diagnostic deworming 
Table 1. Number of Polish primitive horses $(n=124)$ examined of different age groups from nine horse farms in Poland

\begin{tabular}{|c|c|c|c|c|c|c|}
\hline \multirow{2}{*}{ Farm } & \multirow{2}{*}{$\begin{array}{l}\text { Location/ } \\
\text { Region }\end{array}$} & \multirow{2}{*}{$\begin{array}{c}\text { Types of horse } \\
\text { management }\end{array}$} & \multicolumn{4}{|c|}{ Number of samples per age group } \\
\hline & & & $<3$ years & $3-10$ years & $>10$ years & Tota \\
\hline Popielno (1) & W-MR & ST & 11 & 7 & 4 & 22 \\
\hline Popielno (2) & W-MR & FR & 11 & 0 & 0 & 11 \\
\hline Seven Island & W-MR & FR & 9 & 2 & 0 & 11 \\
\hline Majdan & W-MR & SF & 1 & 6 & 7 & 14 \\
\hline Bialowieza & PR & SF & 1 & 3 & 2 & 6 \\
\hline Biebrza & PR & $\mathrm{FR}$ & 4 & 5 & 1 & 10 \\
\hline Narew & PR & SF & 0 & 2 & 0 & 2 \\
\hline Monki & PR & SF & 4 & 4 & 0 & 8 \\
\hline Roztocze (1) & LBR & FR & 7 & 4 & 5 & 16 \\
\hline Roztocze (2) & LBR & ST & 0 & 12 & 1 & 13 \\
\hline Siriusz & $\mathrm{LR}$ & ST & 4 & 7 & 0 & 11 \\
\hline Total & & & 52 & 52 & 20 & 124 \\
\hline
\end{tabular}

Regions: W-M - Warminsko-Mazurskie region, PR - Podlaskie region, LBR - Lubelskie region, LR - Lodzkie region;

Types of horse management: ST - stabled horses, FR - free-ranging horses, SF - semi-free horses.

method after anthelmintic treatment (Kuzmina et al., 2005). All horses examined (except the horses from Popielno) were treated with Equimax paste (ivermectin, $18.7 \mathrm{mg}$ + praziquantel, $140.3 \mathrm{mg}$, Virbac de Portugal Laboratorios LDA, Portugal) at a dose of $1.07 \mathrm{~g}$ of paste per $100 \mathrm{~kg}$ of body weight. Horses from the Popielno were treated with Abamitel-Plus (abamectin, $4 \mathrm{mg}$ + praziquantel, $50 \mathrm{mg}$; Krka, Slovenia) at a dose of $1 \mathrm{ml}$ paste per $20 \mathrm{~kg}$ of body weight. Fecal samples $(200 \mathrm{~g})$ containing expelled gastrointestinal parasites were collected from each horse 24, 36, and 48 hours after treatment. Samples were washed with tap water, pre-fixed in $40 \%$ ethanol and kept in refrigerator $\left(t^{\circ}=+4{ }^{\circ} \mathrm{C}\right)$ until parasites were collected manually and fixed in $70 \%$ ethanol. All helminthes collected were identified under a light microscope by morphological criteria (Ivashkin, Dvojnos, 1984; Dvojnos, Kharchenko, 1994; Lichtenfels et al., 2008). Before identification, the nematodes were clarified in phenol-glycerin solution ( $80 \%$ phenol, $20 \%$ glycerin). Totally, 66,192 parasite specimens were collected and identified.

\section{Statistical analysis.}

Primer 6 software (Clarke, Gorley, 2006) was used for statistical analysis. Taking into account that expulsion of parasites (eggs and adults) into feces is not normally distributed, statistical analysis was performed using the nonparametric Kruskal-Wallis test with significant differences at $p<0.05$.

\section{Results}

\section{EPG-value results}

Coprological examination of the Polish primitive horses showed that strongylid nematodes were the most prevalent parasites at all farms - $95.2 \%$ of horses were infected with strongylids; eggs of Parascaris equorum were detected in $26.6 \%$ and Strongyliodes westeri in $12.9 \%$ (Table 2). Eggs of cestodes were not observed in the fecal samples examined. Analysis of the results revealed a dependence of levels of horse infections with intestinal nematodes (EPG value) with their sex, age and management strategies (Table 3). The level of infection with strongylids was significantly higher in females (average EPG $=923.9 \pm 891.2 \mathrm{SD}$ ), than in males (average $E P G=591.3 \pm 641.7 \mathrm{SD}$ ) (Kruskal-Wallis test; $p<0.05$ ). However, if we include the management strategies (FR, SF ant ST) as a second factor , this dependence of strongylids infection with sex became insignificant $(p>0.05)$. Significant differences in the level of horse infections by $P$. equorum and $S$. westeri between sexes were not found $(p>0.05)$.

Significant differences in strongyle egg counts (EPG) were not observed between horses from the three age groups (Kruskal-Wallis test; $p>0.05$ ). For $P$. equorum, young horses (up to 3 years old) had significantly higher levels of infection as compared to older horses $(p<0.05)$. Eggs of $S$. westeri were detected only in fecal samples from young horses ( $<3$ years old).

In regard to the management strategies, the significant differences in the EPG values were observed only for Strongylidae. For example, on the Popielno and Roztocze farms where horses were stabled and free-ranging, all FR horses had much higher levels of strongylid infection (aver. EPG $=1324.3 \pm 973.8$ SD) than ST horses (aver. EPG $=290.7 \pm 225.1 \mathrm{SD}$ ). The level of strongylid infection in semi-free horses was intermediate. Significant relationships in infections with $P$. equorum and $S$. westeri and type of management strategies were not observed (Kruskal-Wallis test; $p>0.05$ ) (Table 3).

Diagnostic deworming data

Results of the diagnostic deworming examination revealed presence of $P$. equorum (27.4\%), Oxyuris equi (38.7 \%), Habronema 


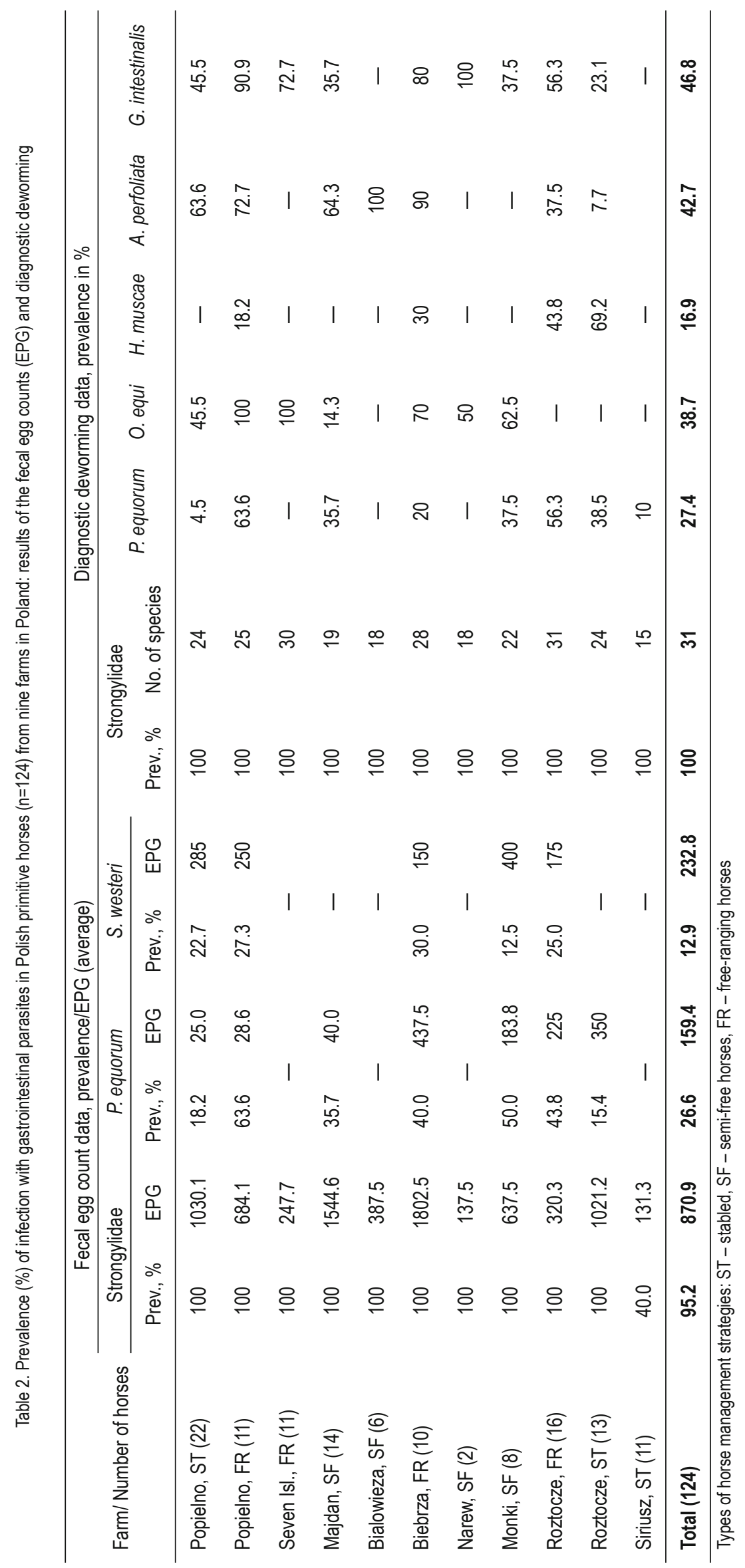


Table 3. The dependence of gastrointestinal parasites infections in Polish primitive horses in regard to sex, age and management strategies: results of the Kruskal-Wallis test $(\mathrm{H})$

\begin{tabular}{lcccccc}
\hline & \multicolumn{2}{c}{ Sex } & \multicolumn{2}{c}{ Age } & \multicolumn{2}{c}{ Management Strategies } \\
\cline { 2 - 7 } & $\mathrm{H}$ & $\mathrm{p}$-value & $\mathrm{H}$ & $\mathrm{p}$-value & $\mathrm{H}$ & $\mathrm{p}$-value \\
\hline \multicolumn{1}{c}{ EPG value data } & & & & & \\
Strongylidae & $\mathbf{4 . 5 1 ^ { * }}$ & $\mathbf{0 . 0 3 4}$ & 2.65 & 0.266 & $\mathbf{3 2 . 0 1}$ & $\mathbf{0 . 0 0 0 0 1}$ \\
P. equorum & 1.84 & 0.175 & $\mathbf{1 4 . 1}$ & $\mathbf{0 . 0 0 0 8}$ & 4.77 & 0.091 \\
S. westeri & 0.83 & 0.36 & $\mathbf{8 . 1 8}$ & $\mathbf{0 . 0 1 6}$ & 1.62 & 0.44 \\
\hline \multicolumn{1}{c}{ Diagnostic deworming data } & & & & \\
Strongylidae & 10.13 & $\mathbf{0 . 0 0 1 5}$ & $\mathbf{6 . 3 4}$ & $\mathbf{0 . 0 4 2}$ & $\mathbf{5 . 2 5}$ & $\mathbf{0 . 0 2 2}$ \\
P. equorum & 2.15 & 0.142 & $\mathbf{5 . 0 8}$ & $\mathbf{0 . 0 2 4}$ & 4.00 & 0.14 \\
O. equi & 1.32 & 0.250 & $\mathbf{2 2 . 1 7}$ & $\mathbf{0 . 0 0 0 1}$ & $\mathbf{2 0 . 3 6}$ & $\mathbf{0 . 0 0 0 3}$ \\
H. muscae & 0.401 & 0.526 & 0.69 & 0.71 & 3.47 & 0.176 \\
A. perfoliata & 2.91 & 0.088 & 1.81 & 0.41 & 3.65 & 0.161 \\
G. intestinalis & 0.062 & 0.803 & 4.48 & 0.11 & $\mathbf{2 0 . 8 8}$ & $\mathbf{0 . 0 0 0 2}$ \\
\hline * statistically significant results are marked in bold & & &
\end{tabular}

muscae (16.9\%), Anoplocephala perfoliata (42.7\%) and Gasterophilus intestinalis (46.8 \%) in the Polish primitive horses examined (Table 2). S. westeri was not found using this diagnostic deworming technique.

A similar analysis of the data on the number of parasites obtained by the diagnostic deworming technique compared to the sex, age groups and different management strategies of the horses also was carried out (Table 3). Similar to the EPG-value data, the Polish primitive horse females had a significantly higher infection with intestinal strongylids than males (Kruskal-Wallis test; $p<0.001$ ). For others parasites (P. equorum, O. equi, H. muscae; $A$. perfoliata and $G$. intestinalis), statistically significant differences between infected males and females were not observed $(p>0.05)$.

Significant correlations between the age of the horse and the level of infections were observed only for Strongylidae, $P$. equorum and O. equi. Polish primitive horses older than 10 years had significantly lower numbers of strongylids than younger horses. In contrast, $P$. equorum and $O$. equi were mostly found in young horses up to 3 years old (Kruskal-Wallis test; $p<0.05$ ). Significant influence of the age of the horse with infections of $H$. muscae, $A$. perfoliata and $G$. intestinalis was not observed $(p>0.05)$ (Table 3 ).

The management strategies affected the level of parasite burdens only for strongylids, 0 . equi and the larvae of the gastric botfly G. intestinalis (Kruskal-Wallis test; $p<0.05$ ). Free ranging horses had much higher number of strongylid nematodes collected in the fecal samples after the diagnostic deworming as compared to the ST and SF horses. The highest numbers of $O$. equi and larvae of $G$. intestinalis also were found in FR horses.

Table 4. Prevalence of gastrointestinal parasite infections in Polish primitive horses $(n=124)$ from nine farms: results of diagnostic deworming

\begin{tabular}{lcccccc}
\hline Farm/ Number of horses & Strongylidae & P. equorum & O. equi & H. muscae & A. perfoliata & G. intestinalis \\
\hline Popielno, ST (22) & 100 & 4.5 & 45.5 & - & 63.6 & 45.5 \\
Popielno, FR (11) & 100 & 63.6 & 100 & 18.2 & 72.7 & 90.9 \\
Seven Isl., FR (11) & 100 & - & 100 & - & - & 72.7 \\
Majdan, SF (14) & 100 & 35.7 & 14.3 & - & 64.3 & 35.7 \\
Bialowieza, SF (6) & 100 & - & - & - & 100 & - \\
Biebrza, FR (10) & 100 & 20 & 70 & 30 & 90 & 80 \\
Narew, SF (2) & 100 & - & 50 & - & - & 100 \\
Monki, SF (8) & 100 & 37.5 & 62.5 & - & - & 37.5 \\
Roztocze, FR (16) & 100 & 56.3 & - & 43.8 & 37.5 & 56.3 \\
Roztocze, ST (13) & 100 & 38.5 & - & 69.2 & 7.7 & 23.1 \\
Siriusz, ST (11) & 100 & 10 & - & - & - & - \\
Total (124) & 100 & 27.4 & 38.7 & 16.9 & 42.7 & 46.8 \\
\hline
\end{tabular}

Types of horse management strategies: ST - stabled, SF - semi-free, FR - free-ranging horses 


\section{Prevalence, \%}

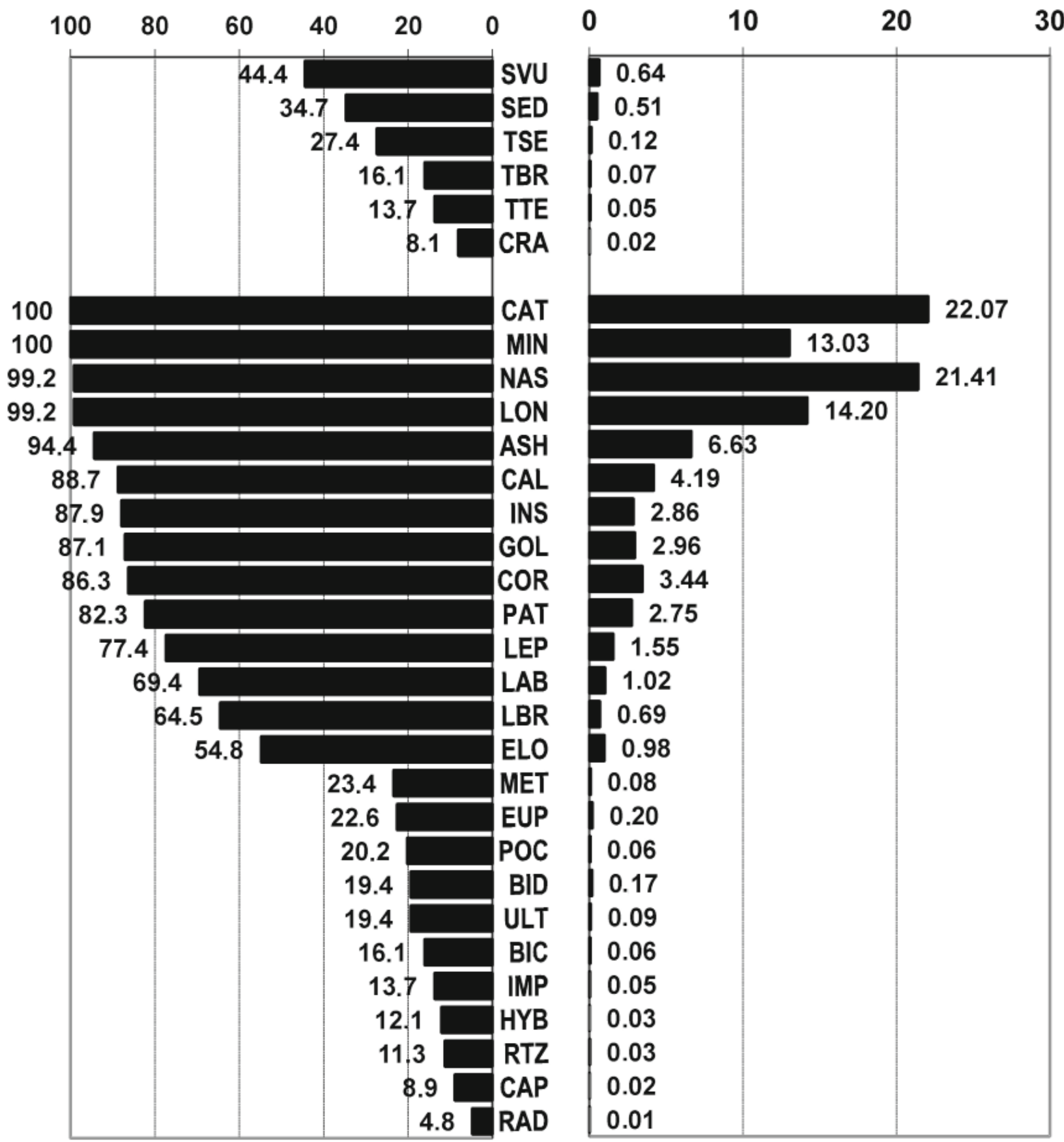

Proportion in the community, \% 30 


\section{Analysis of the strongylid community structure}

Since intestinal strongylids were the most abundant group of parasites found in the Polish primitive horses in this study, the analysis of strongylid communities in horses of different sex, age groups and management strategies was performed. Totally, 31 species from 13 genera were identified: 6 species of large strongyles (subfamily Strongylinae) and 25 species of small strongyles (subfamily Cyathostominae). From 4 to 28 species were observed per horse (average $15.1 \pm 5.1 \mathrm{SD}$ ).

Ten cyathostome species with the prevalence $80-100 \%$ dominated the strongylid community of the Polish primitive horses; together they composed more than $93.5 \%$ of the total number of strongylids collected. Large strongyles (Strongylinae) were found in $54.0 \%$ of the horses examined: from $44.4 \%$ for $S$. vulgaris to $8.8 \%$ for C. acuticaudatum (Fig. 2). Prevalence of separate species of large strongyles varied in horses from different types of management strategies. Free ranging horses had the highest prevalence of large strongyles (75\% for S. vulgaris, $60.4 \%$ for S. edentatus, $56.3 \%$ for T. serratus); SR horses had the lowest prevalence of large strongyles $(26.7 \%$ for $S$. vulgaris, $6.6 \%$ for S. edentatus, $0 \%$ for $T$. serratus); prevalence of large strongyles in ST horses was intermediate (23.9\% for S. vulgaris, $26.1 \%$ for S. edentatus, and $15.2 \%$ for T. serratus).

Analysis of the influence of sex and age of horses to the strongylid community structure revealed that statistically significant differences in prevalence of the separate strongylid species or their proportion in communities were not observed between females and males, or between the three age groups (Kruskal-Wallis test; $p>0.05)$.

Species diversity in strongylid communities of the Polish primitive horses significantly differed between horse farms (Table 2). The lowest number of species (15) was found on the farm "Syriusz", where the horses are kept in stables, and the maximum numbers of strongylid species (30 and 31) were found on farms Seven Island and Roztocze in FR horses.

The types of management strategies of the horses had substantial influence on the strongylid community structure. The FR horses had significantly higher prevalence of large strongyles (Strongylinae) and their proportion in the community was higher compared to horses from others types of management strategies (Kruskal-Wallis test; $p<0.05$ ). Division of the strongylid species into 10 prevalence classes also showed apparent differences in the strongylid community structures between horses from FR, SF and ST conditions (Fig. 3).

\section{Discussion}

This work represents the first extensive analysis of a dependence of infections of gastrointestinal parasites in Polish primitive horses in regard to their age, sex and management strategies. Our parasitological survey was carried out during a five year period at nine breeding farms located in four regions of north-eastern and central
Poland. Previous studies of the gastrointestinal parasite community in Polish primitive horses and species composition of these parasites were carried out only at separate farms and involved smaller number of animals (Gawor, 2000; Romaniuk et al., 2001, 2002, 2003; Slivinska et al., 2009, 2010, 2013). The present study included 124 horses, which composed more than a half of the Polish primitive horse population existing in Poland. Thus, the results obtained in our survey can adequately characterize the current state of infection of these horses with gastrointestinal parasites. The level of infections with gastrointestinal helminthes in Polish primitive horses, using the McMaster method (EPG values) in our study were rather low. The prevalence of strongylid infections

A

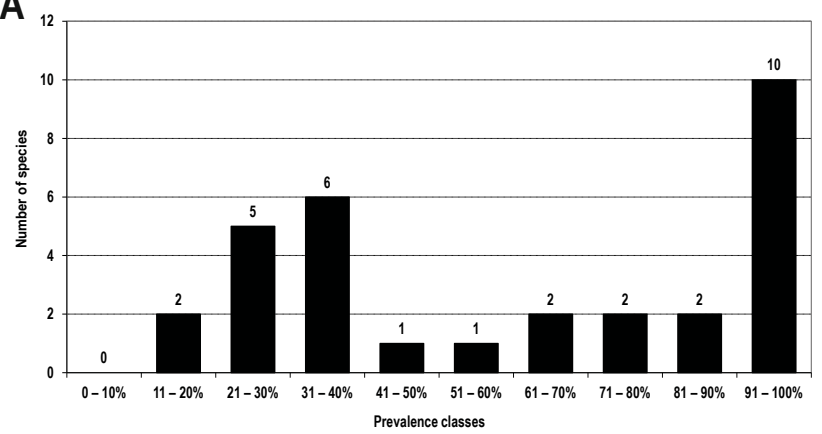

B

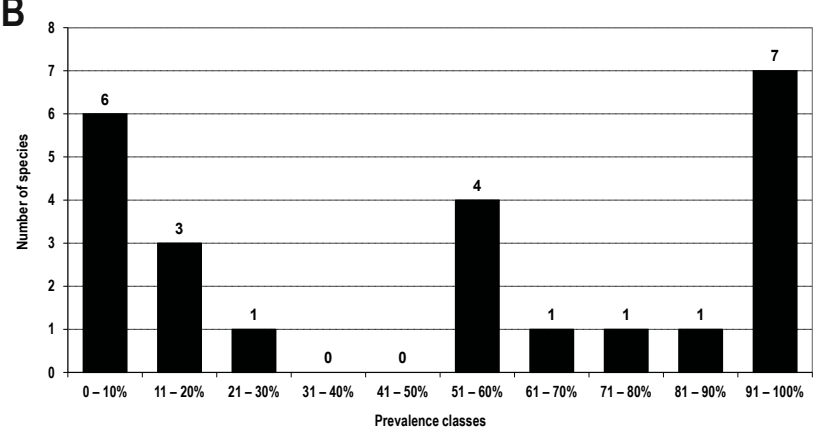

C

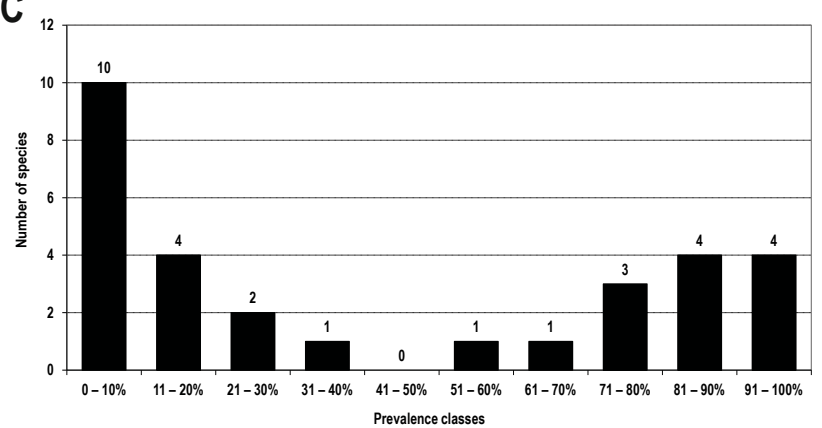

Fig. 3. Distribution of the strongylid species between ten prevalence classes the Polish primitive horses kept under free-ranging $(A)$, semi-free $(B)$ and stable $(\mathrm{C})$ horse-keeping conditions 
close to $100 \%$, an average EPG value of 870.9 , and did not exceed 2 - 3 thousand EPG in the most "contaminated" farms. At the same time, studies of Polish primitive horses carried out in previous years indicated the levels of infections with strongylids of more than 3-4,000 EPG, and even up to 15,700 EPG (Romaniuk et al., 2001, 2002, 2003). The level of infection with $P$. equorum also has decreased in recent years from more than 500 EPG to about 200 EPG (Romaniuk et al., 2001; Slivinska et al., 2013). We believe that such a decrease in infections with the gastrointestinal parasites is primarily due to regular, or even periodic, deworming with highly effective macrocyclic lactone anthelmintic drugs.

The most abundant and pathogenic parasites of the Polish primitive horses documented in this study were strongylids (with a prevalence from $95.2 \%$ with coprological examinations to $100 \%$ in the diagnostic deworming studies) and parascarids (with a prevalence up to $30 \%$ ) (Table 2). Oxyuris equi, $S$. westeri and $H$. muscae were detected less frequently and do not have such pathogenic effects on horses as do strongylids and parascarids (Renemey \& Nielsen, 2013). Habronema muscae has been previously reported in domestic horses in Poland with prevalence of $8 \%$ (Gawor, 1995). Data on prevalence or intensity of infection with $H$. muscae in Polish primitive horses was not found in the literature before our studies (Slivinska et al., 2013). In our opinion, lack of information about Habronema in this indigenous horse breed is connected with methods which were used to collect parasites previously. Traditional quantitative and qualitative coprological methods of examination are not sensitive enough to detect Habronema eggs, but traditional methods of post mortem examination previously were not used to study parasites of the Polish primitive horses. Application of the diagnostic deworming method allowed us to collect $H$. muscae adults and obtain the first data on prevalence of these nematodes in Polish primitive horses. The situation with $S$. westeri is similar to that with Habronema - even strongyliodosis was detected in domestic foals in Poland (Gawor, 1995; Sokół et al., 2015), information about prevalence of these nematodes in the Polish primitive horses was not available before our studies.

Cestodes (A. perfoliata) were found only in horses from five farms in the north-eastern regions of Poland. The botfly $G$. intestinalis larvae were observed at seven farms, but their number was low (less than 4 specimens per horse on average). Our data on prevalence of $G$. intestinalis were similar to previous findings in domestic horses in Poland (from 33 - 40 \% to 47 \%) (Gawor, 1995; Romaniuk \& Niedźwiedź et al., 2013), but lower than in southern regions of Europe - more than $80 \%$ in Italy or south of Russia (Egri et al., 1995; Otranto et al., 2005). Minimal data in regard to the presence of $\mathrm{G}$. intestinalis in Polish primitive horses are available in the literature (Romaniuk \& Snarska, 2002); however their results are not comparable with our present data.

The gastrointestinal parasites we found in the Polish primitive horses are typical parasites of wild and indigenous breeds of horses in Poland and elsewhere in Europe (Romaniuk et al., 1983, 2001, 2002, 2003; Gawor, 2000; Francisco et al., 2009; Kuzmi- na et al., 2009, 2011). We documented more species of intestinal strongylids reported in previous studies in Polish primitive horses (Gawor, 2000; Slivinska et al., 2009). Perhaps this was due to a larger geographic study area utilized in this present study, which included horses from nine farms in four regions of Poland.

In our studies, significant differences in gastrointestinal parasite communities associated with sex were observed only for the intestinal strongylids: females (mares and fillies) had significantly higher numbers of strongylids as compared to stallions and colts, using both the coprological examination data and the diagnostic deworming data (Table 3). Similar differences related to sex of horses were reported by other authors (Bucknell et al., 1995; Romaniuk et al., 2004; Fikru et al., 2005; Francisco et al., 2009; Kornas et al., 2010). In our opinion, such differences were primarily due to inequality of management strategies - traditionally on brood horse farms mares and foals are kept and graze in groups, while stallions, even young ones, are separated from the main herd. This reduces the possibility of parasite exchange between stallions and mares and, consequently, decreases the infection of the former with strongylids transmitted through pasture grazing (Reinemeyer \& Nielsen, 2013). However, analysis of combined influences of sex and management strategies (which were performed on our data) documented that such correlations were found to be insignificant in the Polish primitive horses. We believe that for indigenous horses, the external factors such as management strategies affect the infection levels much more than internal factors. For the other parasites, significant differences in their infection associated with sex were not observed.

Significant differences with infection of intestinal parasites associated with age were observed only for Strongylidae, P. equorum and O. equi (Table 3). Our data are consistent with similar observations on brood domestic horses (Hoglund et al., 1997; Lind et al., 1999; Larsen et al., 2002; Kornas et al., 2010; Kuzmina, 2012), and support the concept on the development of anti-parasite immunity in horses with age (Klei \& Chapman, 1999). Concerning H. muscae, A. perfoliata and $G$. intestinalis, significant differences in the levels of infection of horses of different ages were not detected.

The more obvious differences in parasite infections in Polish primitive horses in our study were associated with the management strategies. The FR horses at all farms examined had higher levels of strongylid infection. In our opinion this finding was primarily associated with infrequent or absent anthelmintic treatments. On the contrary, more frequent deworming in ST horses resulted in a lower EPG values and poorer species biodiversity of the intestinal parasites. In the analysis of species composition of the strongylid communities we found that ST horses harbored the lowest number of species of these nematodes (15), while the highest species biodiversity (30 or 31) was documented in FR horses. Our findings correspond to the results of other authors who conducted similar studies in Poland (Kornas et al., 2006; Pilarczyk et al., 2010), as well as in other countries (Hoglund et al., 1997; Lind et al., 1999; Larsen et al., 2002; Kuzmina et al., 2007, 2009, 2011; Kuzmina, 2012). 
The results of our survey of gastrointestinal parasite infections in Polish primitive horses depending on their age, sex and, especially, management strategies should be taken into account in elaboration of parasite control programs on farms and, in particular, during transportation of horses between farms to prevent spreading of parasites. Taking into account a high resilience of the Polish primitive horses to infection with different groups of gastrointestinal parasites (Romaniuk et al., 2007; Romaniuk \& Jaworski, 2007), as well as the specificity of their management strategies, especially on FR farms, the methods of parasite control (mostly deworming) must not be done too often and, best done, after monitoring studies of the parasite infections. This will prevent the development and spreading of anthelmintic resist intestinal parasites.

\section{Acknowledgments}

The authors thank colleagues from the I. I. Schmalhausen Institute of Zoology of the NAS of Ukraine, Dr. Igor I. Dzeverin for his valuable consultations on statistical analysis of the results, and Dr. Yuriy Kuzmin for his comments to the manuscript, and Prof. Terry R. Spraker from the Colorado State University, Fort Collins Colorado, USA, for his corrections to the manuscript. The authors thank all the staff of the Polish primitive horse farms and reserves for their assistance in field work.

\section{References}

Bucknell, D.G., Gasser, R.B., Beveridge, I. (1995): The prevalence and epidemiology of gastrointestinal parasites of horses in Victoria, Australia. Int. J. Parasitol., 25(6): 711 - 724

CLARKE, K.R., GoRley R.N. (2006): PRIMER v6: User Manual/Tutorial. PRIMER-E, Plymouth, UK

Dvojnos, G.M., Kharchenko, V.A. (1994): Strongylida of wild and domestic horses. Naukova Dumka, Kiev. 234 pp. [In Russian] Egri, B., SÁrközy, P., BÁnHidY, G. (1995): Prevalence of botfly larvae and lice in studs of North Caucasus (Stawropol County, Russia). Acta Vet. Hung., 43(2 - 3): 287 - 289

FIKRU, R., RETA, D., BIZUNESH, M. (2005): Prevalence of equine gastrointestinal parasites in western high lands of Oromia, Ethiopia. Bull. Anim. Health Prod. Afr., 53(3): 161 - 166

Francisco, I., Arias, M., Cortinas, F.J., Francisco, R., Mochales, E., Dacal, V., SuÁrez, J.L., Uriarte, J., Morrondo, P., Sánchez-AndRade, R., Díez-Bańos, P., Paz-Silva, A. (2009): Intrinsic factors influencing the infection by helminth parasites in horses under an oceanic climate area (NW Spain). J. Parasitol. Res., DOI:10.1155/2009/616173

GAWOR, J. (1995): The prevalence and abundance of internal parasites in working horses autopsied in Poland. Vet. Parasitol., 58(1 -2): $99-108$

GAWOR, J. (2000): Occurence of Strongylidae (Nematoda: Strongyloidea) in Polish horses "tarpans” from Popielne Reserve. Wiad. Parazytol., 46: 87 - 92
HERD, R.P. (1992): Performing equine fecal egg counts. Vet. Med., 87: $240-244$

HoDKINSON, J.E. (2006): Molecular diagnosis and equine parasitology. Vet. Parasitol., 136(2): 109 - 116. DOI: 10.1016/j.vetpar.2005.12.006

Hoglund, J., Luungstrom, B.L., Nilsson, O., Lundquist, H., OsterMAN, E., UGGLA, A. (2007): Occurrence of Gasterophilus intestinalis and some parasitic nematodes of horses in Sweden. Acta Vet. Scand., 38, 157 - 165

IVASHKIN, V.M., DvoJnos, G.M. (1984): Identification key of helminth of horses. Kiev: Naukova Dumka, 162 pp. (In Russian)

JaWORSKI Z., JeZIERSKI T. (2006): Husbandry of the Polish Konik horses in reserves and their welfare. Przeg. Hod., 10: 14 - 19 (In Polish)

JAWORSKI, Z. (2007): Invaluable horses. Research in Progress. Breed. Anim., 2(10): 32 - 33

JaWORSKI, Z., JasZCZYCSKA, M. (2004): Program of the breeding of Polish primitive horses, Balice, Project of the Institute of Zootechnics, $55 \mathrm{pp}$.

JeZierski T., JaWORSKI Z., Kaproń M., ŁuKomski S., SŁomiany J. (2012): Polish Studbook of the Polish Konik horses. The program for the maintenance of the Polish Konik horses. PZHK Warszawa, 1 - 26 (In Polish)

JeZIERSKI, T., JaWORSKI, Z. (2008): The Polish Konik horses. The New Library. 658. Westarp Wissenschaften, Hohenwarsleben, 113 - 196 (In German)

KleI, T.R., Chapman, M.R. (1999): Immunity in equine cyathostome infections. Vet. Parasitol., 85 (2 - 3): 123 - 136

Kornas, S., Nowosad, B., Skalska, M. (2006): Dynamic of small strongyle (Cyathostominae) infection in horses under different management systems. Ann. Anim. Sci., 6: 129 - 138

Kornas, S., Cabaret, J., Skalska, M., Nowosad, B. (2010): Horse infection with intestinal helminths in relation to age, sex, access to grass and farm system. Vet. Parasitol., 174: 285 - 291. DOI: 10.1016/j.vetpar.2010.09.007

KownackI, M. (1984): Polish Horses. Warszawa: PWN.

Kuzmina, T.A., Kharchenko, V.A., Starovir, A.I., Dvojnos, G.M. (2005): Analysis of the strongylid nematodes (Nematoda: Strongylidae) community after deworming of brood horses in Ukraine. Vet. Parasitol., 131 (3-4): 283 - 290, DOI: 10.1016/j.vetpar.2005.05.010 Kuzmina, T.A., Kharchenko, V.A., Zvegintsova, N.S. (2007): Comparative study of the intestinal strongylid communities of equidae in the Askania-Nova biosphere reserve, Ukraine. Helminthologia, 44 (2): 62 - 69, DOI: 10.2478/s11687-007-0005-9

Kuzmina, T., Kornaś, S., Basiaga, M., Kharchenko, V., Vyniarska, A. (2011): Biodiversity of strongylids (Nematoda: Strongylidae) communities in domestic horses from Poland and Ukraine. Helminthologia, 48 (2): 77 - 84, DOI: 10.2478/s11687-011-0013-7

KuzminA, T.A. (2012): Analysis of regional peculiarities of strongylids (Nematoda: Strongylidae) biodiversity in domestic horses in Ukraine. Vestn. Zool., 46 (1): P. 9 - 17. DOI: 10.2478/v10058012-0002-4 
KuZmina, T.A., Zvegintsova, N.S. ZhaRKIKH, T.L. (2009): Strongylid community structure of the Przewalski's horses (Equus ferus przewalskii) from the biosphere reserve "Askania-Nova", Ukraine. Vestn. Zool., 43(3): 209 - 215. DOI: 10.2478/v10058-009-0010-1 Larsen, M.M., Lendal, S., Chriel, M., Olsen, S.N., BJorn, H. (2002): Risk factors for high endoparasitic burden and the efficiency of a single anthelmintic treatment of Danish horses. Acta Vet. Scand., 43, 99 - 106. DOI: 10.1186/1751-0147-43-99

LICHTENFELS, J. R. (1975): Helminths of domestic equids. Illustrated keys to genera and species with emphasis on North American forms. Proc. Helminthol. Soc. Wash., 42: 1 - 92

Lichtenfels, J.R., Kharchenko, V.A., Dvojnos, G.M. (2008): Illustrated identification keys to strongylid parasites (Strongylidae: Nematoda) of horses, zebras and asses (Equidae). Vet. Parasitol., 156 (1-2): 4 - 161, DOI: 10.1016/j.vetpar.2008.04.026

Lind, E.O., Hoglund, J., Luungstrom, B.L., Nilsson, O., Uggla, A. (1999): A field survey on the distribution of strongyle infections of horses in Sweden and factors affecting faecal egg counts. Equine Vet. J., 31, 68 - 72. DOI: 10.1111/J.2042-3306.1999.TB03793.X

NiedźWiedź, A., Borowicz, H., Nicpoń, J.M. (2013): Prevalence study in horses infected by Gasterophilus sp. in an eastern region of Poland. Vet. Parasitol., 191(1-2):94 - 96. DOI: 10.1016/j.vetpar.2012.08.023

Otranto, D., Milillo, P., Capelli, G., Colwell, D.D. (2005): Species composition of Gasterophilus spp. (Diptera, Oestridae) causing equine gastric myiasis in southern Italy: parasite biodiversity and risks for extinction. Vet. Parasitol., 133(1): 111 - 118

PAsICKA, E. (2013): Polish konik horse - characteristics and historical background of native descendants of tarpan. Acta Sci. Pol., Med. Vet., 12 (2 - 4): 25 - 38

Pilarczyk, B., Smugala, M., Binerowska, B., Tomza-Marciniak, A., BAKowsKa, M., TYLKowSKA, A. (2010): Prevalence of intestinal parasites of Polish Konik horses - comparison between domestic horses and imported from the Netherlands. Bull. Vet. Inst. Pulawy, 54(2): $171-174$

PRUSKI, W. (1959): Wild horses of Eastern Europe. 1 part. The earliest sources and news about wild horses in Europe. Rocz. Nauk Rol., Serie D, 85: 5 - 131 (In Polish)

PRUSKI, W., JaWOROWSKA, M. (1963): The work and research conducted in Poland on the regeneration of wild horses called Tarpan. Rocz. Nauk Rol., Serie D, Monographie 108: 3 - 110 (In Polish) Reinemeyer, C., Smith, S., Gabel, A., Herd, R. (1984). Herd prevalence and intensity of internal parasites of horses in the USA. Vet. Parasitol., 15 (1): $75-83$

Reinemeyer, C., Nielsen, M. (2013): Handbook of Equine Parasite Control. Wiley-Blackwell, 224 pp.

Romaniuk, K., BugajaK, P., LaWrynowicz, Z. (1983): Infections of the gastro-intestinal parasites of the Polish primitive horse under forest and stable breeding. Wiad. Parazytol., 3: 325 - 333
Romaniuk, K., JaWorski, Z., Snarska, A. (2001): The existence of internal parasites in the primitive Polish horses from forest breeding. Med. Weter., 57 (3), $204-206$

Romaniuk, K., Jaworski, Z., Snarska, A. (2002): Progress of Trichonema and Strongylus invasion in Primitive Polish Horse mares and their foals. Med. Weter., 58 (6), 467 - 469

RomanIUK, K., SNARSKa, A. (2002): Existence of horse botfly Gasterophilus intestinalis eggs on coats of mares, suckling colts and young mares and colts of primitive Polish horses. Med. Weter., 58 (8), $641-643$

Romaniuk, K., Jaworski, Z., Golonka, M., Snarska, A. (2003): Occurrence and dynamics of internal parasite invasions in primitive free-bred Polish horses. Med. Weter., 59 (7), 617 - 619.

RomaniuK, K., ResZKa, K., LASOTA, E. (2004): Influence of animal breeding manner on the occurrence of internal parasites. Wiad. Parazytol., 50(3): 647 - 651

Romaniuk, K., Jaworski, Z., Golonka, M. (2007). Course of internal parasite invasion in the primitive Polish horse herd from woodland breeding. Med. Weter., 63 (1): 87 - 89

RomanIUK, K., JAWORSKI, Z. (2007): Course of strongyles invasion in treated and untreated primitive Polish horses. Med. Weter., 63 (11): 1370 - 1372 (In Polish)

Sokót, R., Raś-Noryńska, M., Michalczyk, M., Raś, A., Rapacz-LeonARD, A., KozIATEK, S. (2015): Estimation of infection of internal parasites in horses from different type of farms. Ann. Parasitol., 61(3):189 - 192. DOI: 10.17420/ap6103.06

SLIVINSKA, K., WRÓBLEWSKI, Z. (2012): Gastro-intestinal parasites of the Polish primitive horse in the Bialowieza National Park, Poland. In Proc. of the VIII Int. S. Conf. "Modern aspects of pathogen, clinic, diagnostics, treatment and prophylaxis of parasitosiss", September 27-28, 2012. Vitebsk, Belorussia: 36 - 38 [In Russian]

SlivinSKA, K., GAWOR, J., JAWORSKI, Z. (2009): Gastro-intestinal parasites in yearlings of wild Polish primitive horses from the Popielno Forest Reserve, Poland. Helminthologia, 46(1): 9 - 13. DOI: 10.2478/s11687-009-0002-2

SlivinSKa K., WróbleWSKI, Z., GAWOR, J., JaWORSKI, Z. (2010): Parasite control of the wild horses (Konik polski Equus caballus and Przewalski horse E. przewalskii) under reserves of Poland and Ukraine. Proceedings of the $6^{\text {th }}$ International Colloquium for Working Equids, Delhi, India: 221 - 224

SlivinSKA, K., Wróblewski, Z., Gawor, J. (2013): Occurrence of gastro-intestinal parasites in Polish primitive horses from the Roztocze National Park, Poland. Vestnik Zoologii, 47(6): 53 - 61. DOI: 10.2478/vzoo-2013-0053

SlivinSKA, K., WróbleWSKI, Z., GAWOR, J. (2016): Gastrointestinal parasites of the Polish primitive horses from the Biebrza National Park. Helminthologia, 53(1): 39 - 46. DOI: 10.1515/ helmin-2015-0065 